\title{
AS EXTERNALIDADES POSITIVAS E NEGATIVAS EM FUNÇÃO DO AVANÇO DA SOJICULTURA
}

\section{ARTIGO ORIGINAL}

MOREIRA, Samya de Freitas ${ }^{1}$

SANTOS, Sara Dorea de Oliveira ${ }^{2}$

SILVA, Raiane Ferreira ${ }^{3}$

LOBO, Ronilson Rosário ${ }^{4}$

JESUS, Edmir dos Santos ${ }^{5}$

JÚNIOR, Antônio Pereira ${ }^{6}$

MOREIRA, Samya de Freitas. Et al. As externalidades positivas e negativas em função do avanço da sojicultura. Revista Científica Multidisciplinar Núcleo do Conhecimento. Ano 04, Ed. 12, Vol. 03, pp. 91-113. Dezembro de 2019. ISSN: 2448-

${ }^{1}$ Graduanda em Engenharia Ambiental. Universidade do Estado do Pará. Centro de Ciências Naturais e Tecnologia.

${ }^{2}$ Graduanda em Engenharia Ambiental. Universidade do Estado do Pará. Centro de Ciências Naturais e Tecnologia.

${ }^{3}$ Graduanda em Engenharia Ambiental. Universidade do Estado do Pará. Centro de Ciências Naturais e Tecnologia.

${ }^{4}$ Graduando em Engenharia Ambiental. Universidade do Estado do Pará. Centro de Ciências Naturais e Tecnologia.

${ }^{5}$ Doutor em Ciência do Clima. Universidade do Estado do Pará. Centro de Ciências Naturais e Tecnologia.

${ }^{6}$ Mestre em Ciências Ambientais. Universidade do Estado do Pará. Centro de Ciências Naturais e Tecnologia. 
0959, Link de acesso: https://www.nucleodoconhecimento.com.br/engenhariaambiental/externalidades-positivas

\section{RESUMO}

As externalidades têm efeitos positivos ou negativos, pois geram custos ou benefícios à sociedade. O objetivo deste estudo foi a realização de uma pesquisa quantiqualitativa, para evidências em relação entre as externalidades e o avanço da sojicultura, no município de Paragominas e, com isso, gerar dados que permitam um equilíbrio adequado. $O$ método aplicado foi 0 indutivo, com abordagem quantiqualitativa, associada a levantamento dos dados documentais com recorte temporal compreendido entre 2008 a 2016, devido a implantação do Projeto Município Verde em 2008. A análise dos dados obtidos indicou que houve uma evolução na área plantada de soja (52.520 ha para 239.163 ha) nos três triênios analisados (2008-2010; 2011-2013; 2014-2016), indicaram também que houve avanço do PIB agropecuário ( $R \$ 101.605 .000,00$ para $R \$ 278.493 .000,00$ ), e consequentemente, ampliação do PIB municipal ( $R \$ 4.290 .238 .000,00$ para $R \$ 6.684 .730 .690,00)$, qualificados como externalidades positivas. Mas, acarretou externalidades negativas como, por exemplo, o desflorestamento, que evoluiu de 2.555.710 ha em (2008-2010) para 2.619.570 ha em (2014-2016). Logo, esse quadro das externalidades negativas pode ser contornado com a aplicação de técnicas sustentáveis (Ex.: técnica de Plantio direto; inoculação de sementes para a Fixação Biológica de Nitrogênio (FBN) no solo, bem como o aproveitamento de áreas da desflorestadas.

Palavras-chave: Desflorestamento, plantio direto, renda, setor agrícola, soja.

\section{INTRODUÇÃO}

A externalidade é uma falha de mercado, e pode ser entendida como um custo ou benefício, resultante da produção de um bem econômico, ou do consumo de bens e serviços, que incide em terceiros, com exceção dos produtores. Origina-se, neste caso, da produção ou consumo, e pode ser positiva, quando gera um benefício, e

Disponível em: https://www.nucleodoconhecimento.com.br/engenharia-ambiental/externalidadespositivas 
negativa, quando acarreta um custo (ALMEIDA, 2013; ANTUNES, 2009; MIRANDA, 2014). A monocultura da soja, por exemplo, carece de uma análise mais aprofundada, por ser uma atividade potencialmente produtora de externalidades positivas e negativas (BALBINOT JUNIOR et al., 2017).

O processo evolutivo brasileiro da sojicultura, tem início em 1941, quando essa cultura adquiriu a primeira referência nacional de produção comercial no Brasil, com o cultivo de 450 toneladas. Oito anos depois, o Brasil elevou a produção a $5.651,33 \%$, com 25.881 toneladas no ano de 1949 , quando adquiriu o primeiro registro internacional como produtor. Dez anos depois, a evolução da soja passou de 151.574 toneladas, e na década seguinte, para 1.056.607 toneladas, um acréscimo de 597,09\%. A partir disso, a soja estabeleceu-se definitivamente como cultura economicamente importante para o país (EMBRAPA, 2015).

Todavia, em 1970, menos de $2 \%$ da produção nacional foi colhida no Brasil central. Contudo, em 1980, essa porcentagem passou para 20\%, em 1990 já era superior a $40 \%$ e, em 2011, a contribuição foi de 60\%, E com tendências a ocupar maior espaço a cada nova safra. Como reflexo desse avanço de produtividade no país, o Brasil ocupa a segunda colocação de maior produtor da oleaginosa, com pequena diferença de produção, e com isso sucede apenas os Estados Unidos (DALL'AGNOL, 2011).

Em outras palavras, a cultura da soja é o expoente do agronegócio brasileiro, e a contínua expansão começa a chamar atenção para os efeitos que derivam dessa produção. As externalidades geradas pela monocultura da soja não se limitam àquelas diretamente relacionadas às áreas destinadas a tal cultura (FIRMINO; FONSECA, 2008).

Ademais, ao considerar que há subprodutos (bens de interesse público gerados pela atividade agrícola), decorrentes da atividade agrícola, com especial atenção para a monocultura da soja, deve-se entender esses subprodutos como as externalidades. É imprescindível chegar a um modelo de remuneração das externalidades, seja por 
subsídios advindos do poder público, seja pela elevação dos preços de tais artigos (GRANZIERA; SAES, 2014).

Em relação as externalidades positivas, a sojicultura destaca-se pelo peso político que possui, pois, promove a implantação de obras de infraestrutura na região a partir do denominado "efeito-arraste", que consiste na atração de outras atividades e/ou investimentos para a região (BRUM; DALFOVO; BENFICA, 2011).

Decerto, o crescimento dos setores envolvidos com a soja, a partir da expansão de áreas agrícolas, tecnologias e investimentos em indústrias processadoras, proporcionam resultados positivos para a população das cidades, como a geração de mais empregos, mais investimento em educação e capacitação profissional, consequentemente, há melhores fontes de renda e serviços (DERANI; SCHOLZ, 2017).

Quanto as externalidades negativas, os biomas e a biodiversidade são diretamente afetados pela expansão da monocultura da soja. A agricultura intensiva, especialmente a ligada ao agronegócio dessa oleaginosa, amplia a participação na conversão da cobertura vegetal nativa. Com o aumento da produção de soja, acarretada pelo maior incentivo do governo, a área plantada também se elevou (33 milhões de toneladas em 2000 para 95 milhões de toneladas em 2016, um acréscimo de $187,88 \%$ ), o que ocasiona o incremento do desflorestamento e, com ele, danos ao meio ambiente (SOUZA; ROCHA; RIBEIRO, 2013).

Em consequência disso, a perda de biodiversidade é a principal resposta ambiental ao desflorestamento e é, também, totalmente irreversível, quando houver coevolução, isto é, uma evolução interdependente das espécies. O desflorestamento destrói habitats de várias espécies animais e vegetais, e põe em risco a existência das mesmas (ARAÚJO, 2014).

Além disso, estudos (NOBRE et al., 2009; SANTOS et al., 2011), reforçam a tese, de que, o avanço da soja e a conversão da cobertura vegetal, podem provocar sérias alterações hidrológicas e climáticas regionais como, por exemplo, o aumento da

Disponível em: https://www.nucleodoconhecimento.com.br/engenharia-ambiental/externalidadespositivas 
temperatura, mudanças nos padrões de chuvas e alteração na disponibilidade de água. A monocultura da soja também pode ocasionar o empobrecimento e contaminação do solo, devido ao uso indiscriminado de fertilizantes e agrotóxicos (DEUS; BAKONYI, 2012).

Então, o avanço da sojicultura provoca externalidades positivas e negativas que necessitam ser estudadas, o que justifica essa pesquisa, cuja relevância é incrementada pela elaboração de informações necessárias para estimular as externalidades positivas e minimizar as negativas e, por fim, alcançar o objetivo, que é a realização de uma pesquisa quantiqualitativa, em relação as externalidades no município de Paragominas, e o avanço da sojicultura, além de gerar dados que permitam um equilíbrio adequado.

\section{REVISÃO DA LITERATURA}

Em território brasileiro, a soja tem sido a cultura que mais cresce em área cultiva, e a extraordinária expansão de produção nos últimos 20 anos é explicada pelo aumento da área plantada e a produtividade (KUPLICH, CAPONE; COSTA, 2018). Essa área cultivada teve aumento de $378,5 \%$ e a produtividade avançou $64,2 \%$ nas décadas de 1970 a 2000 (PAMPLONA, 2017). Em consequência, a oleaginosa proporciona grande capacidade ao setor agrícola brasileiro, devido à importância territorial (27,7 milhões de hectares plantados em 2012/2013, o equivalente à $52 \%$ dos cultivos temporários), embora nem sempre tenha sido assim (ARAÚJO; PONTE, 2015).

Isso ocorreu devido à migração gradativa para o Paraná, expandiu-se até o centrooeste, inicialmente pelo Mato Grosso do Sul, e posteriormente para outros estados (GAZZONI, 2013; SILVA; RODRIGUES, 2016). Conforme os dados da Companhia Nacional do Abastecimento - CONAB (OLIVEIRA NETO, 2017), atualmente, cinco estados localizados na Região Centro-Sul do Brasil (Goiás, Mato Grosso, Mato Grosso do Sul, Paraná e Rio Grande do Sul) concentram 75\% da área cultivada com soja (25,8 milhões de hectares) e $77 \%$ da produção nacional $(79,25$ milhões de toneladas).

Disponível em: https://www.nucleodoconhecimento.com.br/engenharia-ambiental/externalidadespositivas 
A consequência dessa migração, tornou-se 0 papel importante para 0 desenvolvimento dos municípios, como ocorre em Sorriso - MT, que apresenta bons índices socioeconômicos, como a passagem da renda per capita de aproximadamente $R \$ 7.846,00$ em 1999 para $R \$ 25.935,00$ em 2005. Esse crescimento econômico pode ser notado também em relação ao Produto Interno Bruto - PIB e, segundo a Secretaria da Fazenda de Mato Grosso, era de $R \$ 207$ milhões em 1998, chegou a $R \$ 706$ milhões em 2003, o que significa um crescimento de $342 \%$ em cinco anos. Desse total, a soja participa com $40 \%$ e, considerando todo o setor primário do município, essa participação cresce para 60\% (FREDERICO, 2011; GIARETTA, 2017).

Isso pode ser constatado pela expansão da área semeada com soja que cresceu, em relação à área total do município, de 40,7\% em 2000 para 63,7\% em 2006. Mas, parte do desflorestamento em Sorriso, deve-se diretamente ao plantio da oleaginosa, que ocupa o segundo lugar entre os municípios mato-grossenses com maior percentual de desflorestamento, o equivalente a 68,3\%. A área desflorestada em Sorriso entre 2000 e 2006 correspondeu a 12,17\% da área total do município (BRUM, DALFOVO; AZUAGA, 2009).

No município de Sinop - MT, a soja contribuiu positivamente para que outros setores apresentassem também um progresso, como, por exemplo, o setor industrial e de serviços, que tiveram, respectivamente, em 2004 uma participação no PIB do município, em R\$ 95.535,00 e R\$347.529,00 (BRUM; DALFOVO; BENFICA, 2011).

Outro município, Cristalina - GO, é um dos maiores produtores de soja ( $1^{\circ}$ no ranking estadual e $6^{\circ}$ no nacional) e a elevação do PIB, além da consequente inserção no mercado nacional e internacional, deu status a cidade. A implementação de estruturas físicas armazenadoras objetivando acomodar o produto final das plantações, gerou a inserção e transformação social, vez que estas medidas criam empregos que podem absorver parte do proletário marginal, de modo a intensificar o setor econômico local (FERNANDES; PESSÔA, 2011). 
Impulsionada pela supersafra de soja, a agropecuária do Rio Grande do Sul - RS, evoluiu em 2013, e o Estado registrou o segundo maior PIB agropecuário do Brasil, (12\% do total brasileiro), e ficou apenas atrás do Paraná (12,5\%). Foi um avanço significativo em relação a 2012, quando o Rio Grande do Sul contribuiu com 8,1\% na geração de riquezas no primeiro setor. A melhora de desempenho também garantiu a ultrapassagem (no ranking de produção anual) de outros Estados, tradicionalmente à frente do RS, como Mato Grosso, Minas Gerais e São Paulo (BORGES; SIMÕES; TRINDADE, 2016).

Todavia, o rápido crescimento da produção da soja vem acompanhado de diversos problemas na área social e, principalmente, na área ambiental, visto que, a expansão da demanda sojícola atinge o bioma amazônico, um dos mais ricos em biodiversidade do planeta, e gera preocupação não só para a sociedade brasileira, mas também para os países consumidores dessa produção (MANGATTO JUNIOR; OLIVEIRA; SILVA, 2017; RIVERO et al., 2009).

No contexto amazônico, principalmente no caso de Santarém - PA, as terras que dão margem a expansão produtiva da soja em larga escala, podem ser as terras degradadas pelas pastagens estabelecidas anteriormente, as terras especuladas por grandes produtores da agricultura mecanizada, ou podem ser até mesmo as florestas nativas que, embora intocadas pelo homem, têm sido as mais usadas recentemente, devido à escassez de terras aptas à produção mais próxima aos centros de escoamento (ARAÚJO; PONTE, 2015). Em virtude disso, a soja, aliada a criação de gado e a atividade madeireira são os maiores vetores de desflorestamento (MAGNO et al., 2013).

Nesse município, os impactos sobre as águas são vistos diariamente, braços de rios e igarapés importantes já sumiram ou estão em processo de assoreamento, animais silvestres também estão desaparecendo ou invadindo áreas urbanas. O plantio ilegal da soja sobre as nascentes, destrói as fontes d'água e faz com que o volume dela seja reduzido, e origina, dessa forma, vários crimes ambientais (BROCHADO, 2017; OLIVEIRA; SANTANA, 2012). 
Em consequência disso, a soja representa uma poderosa ameaça à biodiversidade amazônica, pois ela justifica grandes projetos de infraestrutura de transporte, que, por sua vez, iniciam uma cadeia de eventos conduzidos à destruição de habitats naturais em extensões elevadas, além das áreas plantadas diretamente com a soja. Tais fatos tornam a soja muito mais prejudicial ao meio ambiente que outras culturas (DOMINGUES; BERMANN, 2012)

Por conseguinte, a migração do cultivo da soja do norte do Mato Grosso para o sul da região Amazônica tem causado inúmeras alterações climáticas. Estudos (ARTAXO et al., 2014; GONZALES et al., 2013; NOBRE et al., 2009; SANTOS et al., 2011) revelam que isso ocorre devido ao desflorestamento desenfreado das florestas do Bioma, e muito se deve ao avanço da soja. Por isso, se reforça a tese de que, com o avanço da soja e desflorestamento de imensas áreas, o clima na região é diretamente afetado e, altera de maneira brusca os períodos chuvosos e as demais variáveis associadas a isso (SANTOS, C; SATYAMURTY; SANTOS, E. 2012).

Tais mudanças, também ocorreram no bioma Cerrado e, alterou as estruturas do ecossistema da região, onde a vegetação nativa é substituída por lavouras de soja ou o solo seco e ácido, além de passar por transformações para adaptar-se a receber o plantio, o que prejudica a exploração de subsistência das famílias que vivem dos recursos naturais oferecidos pelo Bioma Cerrado, como plantas ornamentais e medicinais, frutos do Cerrado, etc. (QUEIROZ, 2009).

Ademais, um estudo (IRIGARAY et al., 2011) realizado na Bacia do Alto Paraguai, a qual abriga o bioma Pantanal, afirmou que a planície alagável desse bioma, apresenta uma relação de interdependência com os ecossistemas localizados no entorno dele. Logo, quaisquer alterações podem se tornar uma ameaça a biodiversidade do sistema Pantanal, a exemplo do uso e ocupação do solo nesse bioma, que possui uma grande produção de soja. No entanto, mesmo com a importância ecológica do Pantanal, até $2004,44 \%$ da área de cobertura nativa da Bacia do Alto Paraguai foi alterada. 
Outro problema ocorreu em Goiás, onde o empobrecimento genético do solo é o mais crítico nas práticas agrícolas vigentes nessa região do Cerrado, que geralmente se focam na monocultura da soja, o que torna, gradualmente, o solo infértil e impróprio até mesmo para a produção agrícola. A introdução de espécies invasoras na região, alteram, de modo negativo, o sistema natural presente, o que propicia o aparecimento de pragas e doenças, que afetam não só os recursos naturais, mas também a produção agrícola (MATOS; PESSÔA, 2012).

Além disso, no município de Cristalina, no mesmo estado, as lavouras de oleaginosas geram irremediáveis prejuízos às riquezas hídricas da região, pois, além de utilizar indiscriminadamente as reservas de água, ainda prejudicam com a poluição causada pela aplicação de insumos e defensivos agrícolas, que são despejados por equipamentos de irrigação nas lavouras, com objetivo de intensificar a produção. Esses mesmos produtos que corrigem a deficiência nutritiva dos solos e ainda, combatem às pragas, ao caírem no solo são absorvidos e alcançam os lençóis freáticos e, em certos casos, as nascentes dos mananciais hídricos (ABDALA; RIBEIRO; FERREIRA, 2016).

Só para ilustrar: as questões fundiárias somam-se aos efeitos decorrentes da especialização produtiva na soja. O crescimento médio anual do número de conflitos no campo, foi de 7,64\% entre 1990 e 2013. De fato, a ocupação de territórios para o cultivo da soja pressiona as reservas florestais, bem como as áreas destinadas à agricultura de pequeno porte e à extração vegetal, ocupadas por agricultores familiares, povos indígenas e outros povos tradicionais (CPT, 2016).

No Pará, embora inicialmente a soja tenha sido plantada em áreas degradadas, na região do Baixo Amazonas, observam-se casos de plantios processados em cima de áreas de florestas derrubadas ou queimadas. Aliás, nessa região a soja atingiu também áreas ocupadas tradicionalmente por agricultores familiares, nas quais ocorreram aquisições e expulsões das terras, em um processo de substituição das culturas originárias, como milho, feijão, macaxeira, frutas e hortaliças (SILVA, 2008). 
Com a ajuda do Greenpeace, as comunidades locais têm conseguido identificar os impactos da soja no oeste do estado do Pará. As entidades locais põem em dúvida o desenvolvimento da região com a chegada da soja, em face dos inúmeros impactos negativos identificados, como a degradação urbana, carência de hospital que abranja toda a cidade e educação de má qualidade (OLIVEIRA; SANTANA, 2012).

Em Cristalina - GO, o trabalhador rural que foi expulso do campo devido ao uso de maquinários, provoca o êxodo rural e o inchaço na cidade, que não tem estrutura física ou social para recepcionar esta mão-de-obra desqualificada. Logo, são considerados proletários marginais, que precisam e criam novas formas de sobreviver, influenciam o comércio informal, o número de desempregados, desabrigados, e consequentemente, o aumento da violência urbana (FERNANDES; PESSÔA, 2011).

Estes cenários facilitam a compreensão das externalidades positivas e negativas, provocadas pela expansão do agronegócio da soja, que adversamente aos bons resultados obtidos financeiramente, impõe custos ambientais consideráveis num processo contínuo de degradação (DELAZERI, 2016).

\section{METODOLOGIA}

\subsection{MÉTODO}

Para elaboração desse estudo, aplicou-se as sínteses redigidas por cinco pesquisadores acerca das exposições sobre métodos de pesquisa (Quadro 1).

Quadro 1 - Os métodos de pesquisa utilizados.

\begin{tabular}{|l|l|l|l|}
\hline PESQUISADOR & ANO DA & MÉTODOS & CARACTERÍSTICAS \\
& PUBLICAÇÃO & & \\
\hline $\begin{array}{l}\text { Silveira; } \\
\text { Córdova }\end{array}$ & 2009 & Indutivo & $\begin{array}{l}\text { Parte-se da observação de } \\
\text { fatos ou fenômenos cujas } \\
\text { causas se deseja } \\
\text { conhecer. Particularmente, }\end{array}$ \\
\hline
\end{tabular}

Disponível em: https://www.nucleodoconhecimento.com.br/engenharia-ambiental/externalidadespositivas 


\begin{tabular}{|c|c|c|c|}
\hline & & & $\begin{array}{l}\text { no município de } \\
\text { Paragominas, estudou-se } \\
\text { a expansão da soja como } \\
\text { um incremento do } \\
\text { desflorestamento local. }\end{array}$ \\
\hline $\begin{array}{l}\text { Prodanov; } \\
\text { Freitas }\end{array}$ & 2013 & $\begin{array}{l}\text { Abordagem } \\
\text { quantiqualitativa }\end{array}$ & $\begin{array}{l}\text { A utilização conjunta da } \\
\text { pesquisa quantitativa e } \\
\text { qualitativa, permite coletar } \\
\text { mais informações do que } \\
\text { se poderia conseguir } \\
\text { isoladamente, ao gerar } \\
\text { abrangência dos dados e } \\
\text { maior compreensão acerca } \\
\text { dos problemas estudados. }\end{array}$ \\
\hline $\begin{array}{l}\text { Sakamoto; } \\
\text { Silveira }\end{array}$ & 2014 & $\begin{array}{l}\text { Natureza } \\
\text { aplicada }\end{array}$ & $\begin{array}{l}\text { Procura-se gerar } \\
\text { conhecimentos para } \\
\text { aplicação prática, } \\
\text { orientados à solução de } \\
\text { problemas específicos ao } \\
\text { envolver verdades e } \\
\text { interesses locais. }\end{array}$ \\
\hline Severino & 2017 & $\begin{array}{l}\text { Procedimento } \\
\text { exploratório }\end{array}$ & $\begin{array}{l}\text { Propõe-se fornecer maior } \\
\text { familiaridade com } \\
\text { problema de pesquisa, de } \\
\text { forma a torná-lo mais } \\
\text { explícito, pode envolver } \\
\text { levantamento bibliográfico, } \\
\text { entrevistas com pessoas } \\
\text { experientes no problema } \\
\text { pesquisado e análise de }\end{array}$ \\
\hline
\end{tabular}

Disponível em: https://www.nucleodoconhecimento.com.br/engenharia-ambiental/externalidadespositivas 
exemplos que estimulem a compreensão.

Fonte: autores (2019).

Foram consultadas as seguintes bases informacionais: (1) Instituto Brasileiro de Geografia e Estatística (IBGE), onde foram coletadas informações a respeito da produção agrícola da lavoura de soja em Paragominas, as quais envolveram o valor da produção, a produção em toneladas (t.) e a área plantada (ha), calculados pela Pesquisa Agrícola Municipal, (2) Instituto Nacional de Pesquisas Espaciais (INPE), com base no Programa de Desflorestamento da Amazônia (PRODES) Digital, para o levantamento de informações sobre o desflorestamento no município e (3) Agência Nacional de Águas (ANA), com base no portal eletrônico HidroWeb, para coletar dados da precipitação total anual.

Como base para a Revisão da Literatura, foram utilizados periódicos científicos disponíveis nas seguintes bases informacionais: (4) portal da Coordenação de Aperfeiçoamento de Pessoal de Nível Superior (CAPES); (5) banco de dados bibliográficos da Scientifc Electronic Library Online (SciELO) e (6) Google Acadêmico.

Para análise da relação "área desflorestada e o incremento da área plantada da cultura de soja", aplicou-se a metodologia utilizada por Rivero et al. (2009). Tal análise foi efetuada nos anos de 2008 a 2016, e as taxas de desflorestamento observadas para o mesmo período. As análises envolveram estudos de Correlação de Pearson entre tais variáveis, com o objetivo de confirmar ou não, a existência dela, entre essas variáveis.

Os dados obtidos foram organizados em arranjo tabular e tratados estatisticamente com o uso de planilhas eletrônicas contidas no software Microsoft Excel (2016) e a Correlação de Pearson, com valores para $r$, obtidos com o uso de planilhas eletrônicas elaboradas a partir do software BioEstat - versão 5.3 (AYRES et al., 2007), e uso da escala (Tabela 01) utilizada por Porto; Jesus; Pereira Júnior (2017). A partir da organização dos dados, foram elaborados gráficos com o software OriginPro 9. 64

Disponível em: https://www.nucleodoconhecimento.com.br/engenharia-ambiental/externalidadespositivas 
(2012), para demonstrar a interação entre as variáveis estudadas. $E$, quanto a elaboração das tabelas, estas foram elaboradas em planilhas eletrônicas contidas no software Microsoft Word (2016).

Tabela 1 - Escala empregada para a caracterização do tipo de correlação entre as variáveis.

\begin{tabular}{|l|l|}
\hline $\begin{array}{l}\text { Correlação de Pearson } \\
(r)\end{array}$ & Relação \\
\hline $\mathbf{0}$ & Inexistente \\
\hline $\mathbf{0 , 1 0 - 0 , 3 0}$ & Fraca \\
\hline $\mathbf{0 , 4 0 - 0 , 6 0}$ & Moderada \\
\hline $\mathbf{0 , 7 0}-\mathbf{1 , 0 0}$ & Forte \\
\hline
\end{tabular}

Fonte: Porto; Jesus; Pereira Júnior (2017).

\section{2 ÁREA DE ESTUDO}

A pesquisa foi realizada no município de Paragominas (Figura 01), localizado na região Sudeste do Estado do Pará e situado a 02059'08" S e 47019'57" W. A área do município equivale cerca de 19.342,254 km² e a população é estimada em 110.026 habitantes, com densidade populacional de 5,69 hab./km² (IBGE, 2017a). 
Figura 1 - Mapa da localização do município de Paragominas - PA.

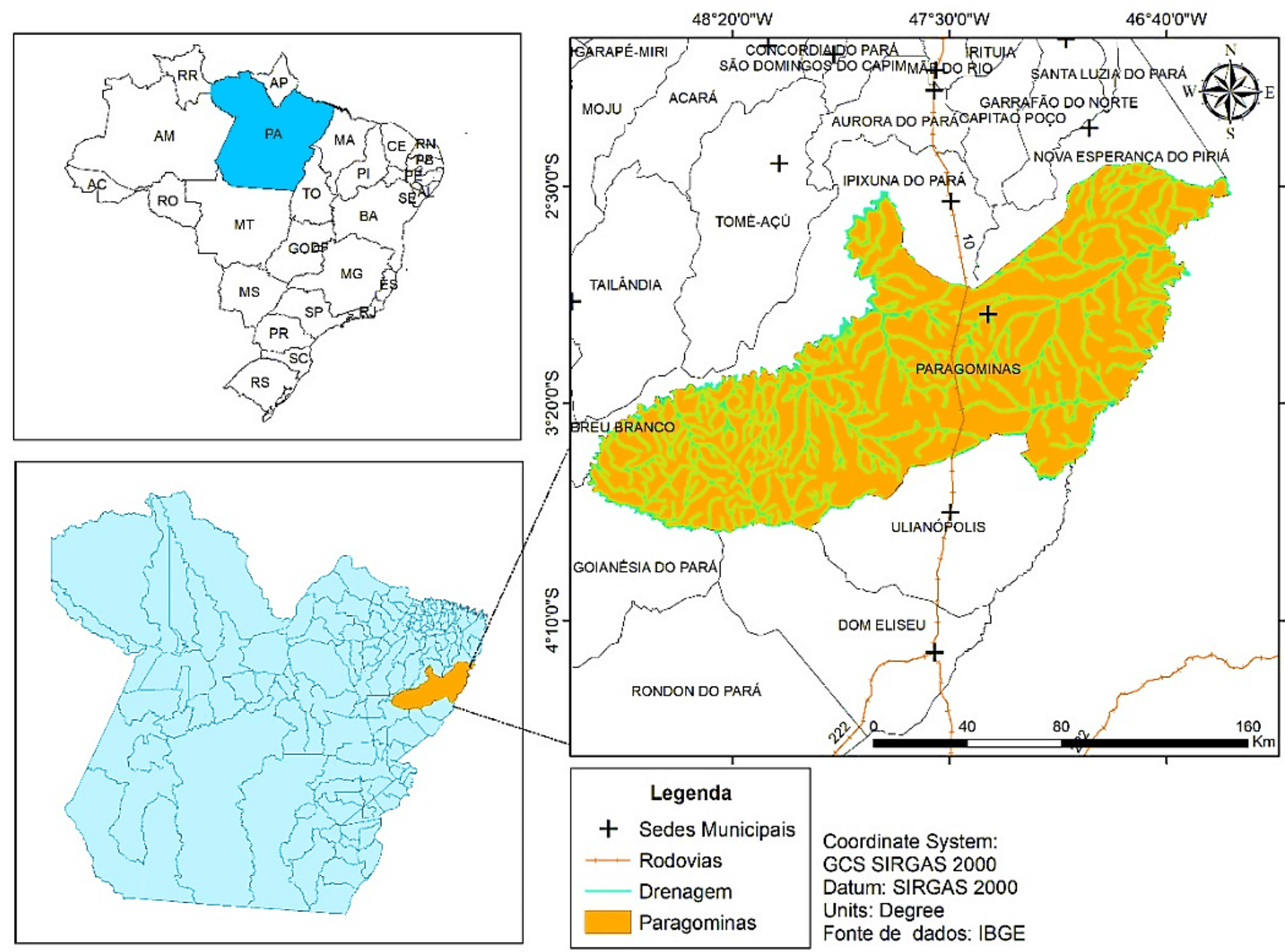

Fonte: autores (2019).

Quanto a caracterização geofísica do município, o clima é classificado como Aw (tropical chuvoso com estação seca bem definida), com médias anuais de precipitação, umidade relativa e temperatura de $1.743 \mathrm{~mm}, 81 \%$ e $26,3{ }^{\circ} \mathrm{C}$, respectivamente, verificando-se no período de julho a novembro baixa disponibilidade hídrica; a vegetação é classificada em floresta equatorial subperenifólia densa submontana, floresta equatorial densa das terras baixas e floresta equatorial perenifólia densa aluvial; possui altitude média de $89 \mathrm{~m}$; o solo é predominantemente (95\%) do tipo Latossolo Amarelo, e a malha hidrográfica é composta por duas bacias principais: a do rio Capim e a do rio Gurupi (PINTO et al., 2009).

Uma das principais atividades econômicas vigentes, é voltada para a agricultura, onde os cultivos preponderantes são de soja (Glycine spp.), milho (Zea mays L.), mandioca

$\mathrm{RC}: 42368$

Disponível em: https://www.nucleodoconhecimento.com.br/engenharia-ambiental/externalidadespositivas 
(Manihot esculenta Crantz) e girassol (Helianthus annuus L.). O município se diferencia muito, dos demais da região, quanto à forma praticar a agricultura, e no aparelhamento das propriedades, visto que é normal encontrar produtores que utilizam um alto nível tecnológico (ALVES; CARVALHO; SILVA, 2014).

Contudo, semelhante às áreas cultivadas com grãos na Amazônia, neste município, se pratica o sistema de cultivo convencional ou tradicional. Este, caracteriza-se pela utilização intensiva da mecanização e do monocultivo, deixando, na maioria das vezes, o solo exposto, tendo como consequências a perda de matéria orgânica e a erosão (SOUZA et al., 2017).

\section{RESULTADOS E DISCUSSÃO}

\subsection{QUANTO A PRODUÇÃO DE SOJA}

Os dados obtidos sobre a produção da soja indicaram que houve tendência de crescimento na produção de soja em Paragominas durante o período analisado, ou seja, 2008 a 2016 (Figura 02).

Figura 2 - Evolução da área plantada de soja no município de Paragominas - PA.

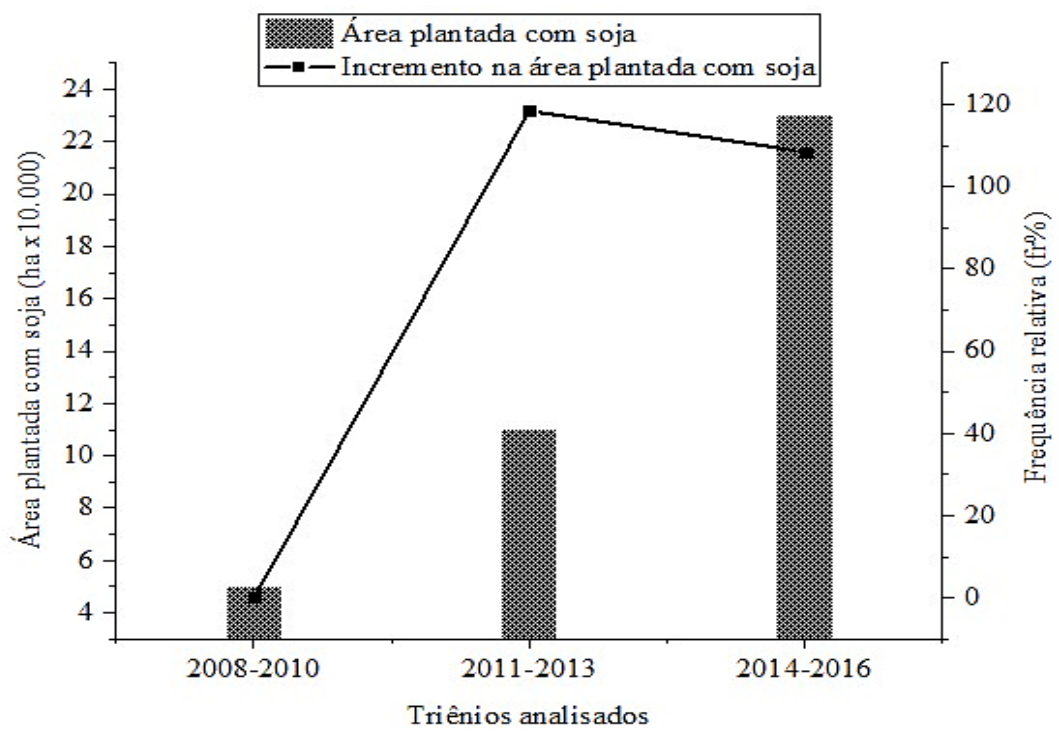

Fonte: IBGE (2017b).

RC: 42368

Disponível em: https://www.nucleodoconhecimento.com.br/engenharia-ambiental/externalidadespositivas 
Percebeu-se, a partir da análise dos dados, que no primeiro triênio (2008-2010) a área plantada de soja correspondeu a 52.520 ha; no segundo triênio (2011-2013), a área destinada para o cultivo de soja foi equivalente a 114.720 ha $(118,43 \%)$. Por fim, no terceiro triênio (2014-2016) a área plantada correspondeu a 239.163 ha $(108,47 \%)$, com uma tendência involutiva $(-9,96 \%)$.

Estudos efetuados nos municípios de Aceguá, Bagé e Dom Pedrito (RS), realizado por Kuplich; Capone; Costa (2018) corroboram para o estudo realizado no município de Paragominas (PA), pois concluíram que a área plantada de soja em 2015 foi, respectivamente, 250, 52 e 38 vezes maior em relação ao primeiro ano de análise (2000). De acordo com o estudo, em Aceguá a área plantada de soja em 2015 aumentou 1.150\% em relação a 2005; no município de Bagé, a área plantada entre 2005 e 2015 cresceu cerca de 191,7\%. E, no município de Dom Pedrito, em 2015, a área plantada aumentou 204\% e distribuiu-se por todo o município. Na pesquisa realizada em Paragominas foi constatado que houve crescimento paralelo entre os anos de 2008 a 2016.

Outro estudo que foi efetuado por Brochado (2017), no município de Santana do Araguaia (PA), grande parte de áreas antes destinadas para pasto, estão voltadas para o cultivo da soja. No Pará, a produção da oleaginosa concentra-se, principalmente, nos municípios da região sul e, também tem expressiva produção no município de Santarém, na região do Baixo Amazonas. Nos municípios de Paragominas, Dom Eliseu, Ulianópolis e Rondon do Pará a safra de 2016 alcançou cerca de 180 mil ha de área plantada de soja. Então, ficou evidente que o crescimento da sojicultura no município analisado, não é obra do acaso.

\subsection{QUANTO A ÁREA DESFLORESTADA}

Em relação à área desflorestada no município de Paragominas, observou-se, por meio dos dados, que houve uma tendência ao crescimento da área total nos triênios analisados (Figura 3). 
Figura 3 - Evolução da área desflorestada no município de Paragominas - PA.

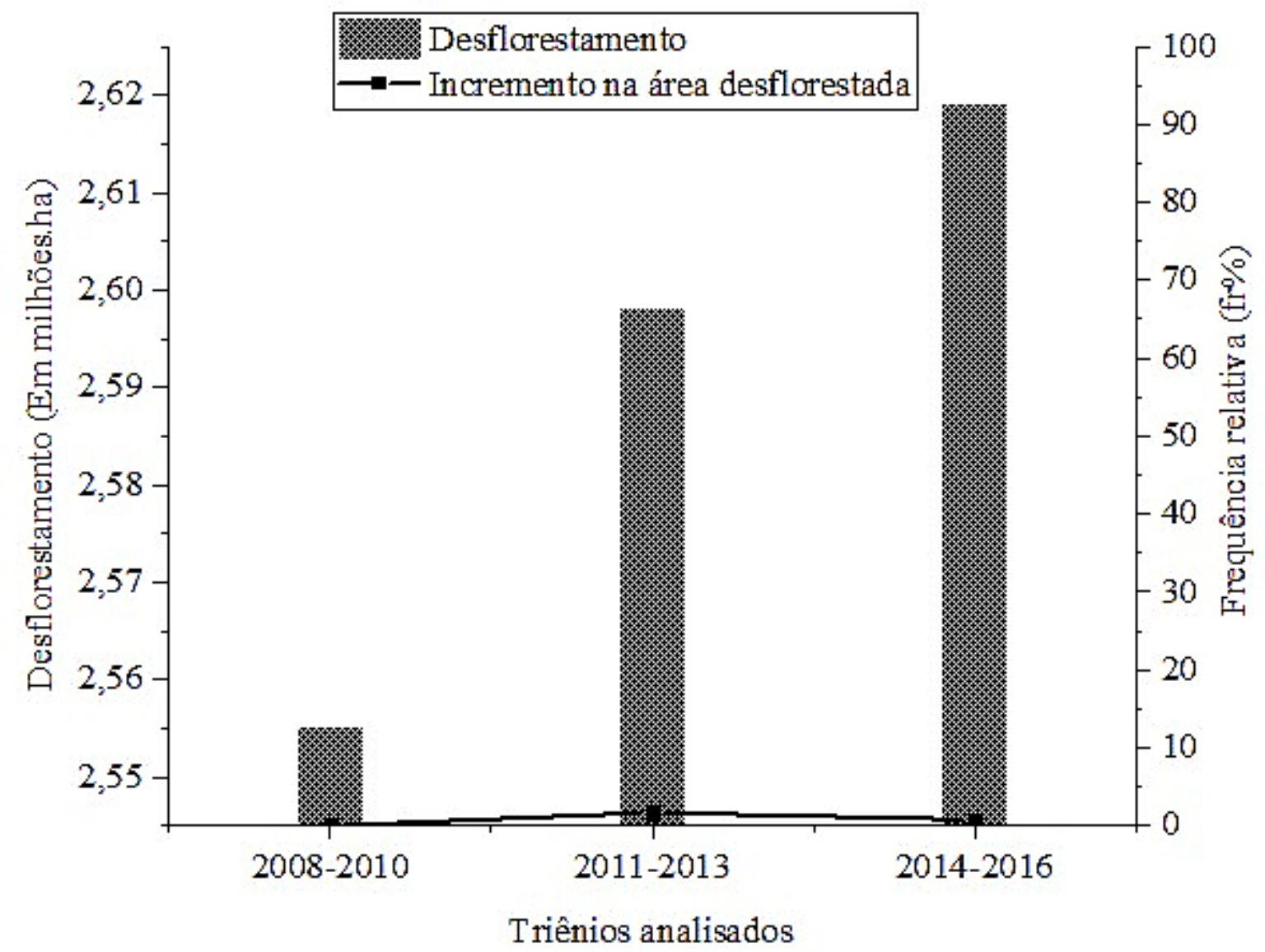

Fonte: PRODES Digital (2017).

Constatou-se, a partir da análise dos dados que, no primeiro triênio (2008-2010) a área desflorestada correspondeu a 2.555.710 ha; no segundo triênio (2011-2013) chegou a 2.598 .920 ha $(1,69 \%)$. Por fim, no terceiro triênio (2014-2016) o desflorestamento correspondeu a 2.619 .570 ha $(0,79 \%)$, com tendência involutiva ($0.9 \%$ ). Os dados indicaram também que, apesar da tendência de crescimento da área desflorestada, ocorreu uma tendência a diminuição entre o segundo e o terceiro triênio, o que denota a presença da atuação de medidas reguladoras municipais, as quais contribuíram para a redução dos índices de desflorestamento.

Na pesquisa realizada por Delazeri (2016), nos municípios do Pará que compõem o Arco do Desmatamento (Altamira, Brasil Novo, Cumaru do Norte, Dom Eliseu,

Disponível em: https://www.nucleodoconhecimento.com.br/engenharia-ambiental/externalidadespositivas 
Itupiranga, Marabá, Novo Progresso, Novo Repartimento, Pacajá, Paragominas, Rondon do Pará, Santa Maria das Barreiras, Santana do Araguaia, São Félix do Xingu, Tailândia e Ulianópolis), foi indicado que a queda nas taxas de desflorestamento pode ser atribuída às políticas ambientais (Plano de Ação para Prevenção e Controle do Desmatamento na Amazônia Legal (PCDAm), introduzidas na segunda metade dos anos 2000. Em Paragominas, esse processo ocorreu em 2008, a partir da implantação do "Projeto Município Verde", com a elaboração de um pacto contra o desflorestamento entre o poder público e a sociedade local.

$\mathrm{Na}$ análise anual dos dados obtidos, verificou-se que entre 2008 e 2016, uma tendência ao crescimento da área desflorestada, uma vez que, no ano de 2008, essa taxa era equivalente a 841,540 ha e, oito anos depois, evoluiu para 875,350 ha em 2016, ou seja, uma elevação de 4,01\% neste período.

O estudo efetuado por Pamplona (2017), no município de Barreiras - BA, concluiu que a evolução do desflorestamento no período de 1990 a 2016, mostrou tendência evolutiva em $24 \%$ e, em uma análise mais detalhada, esse autor acrescentou que, em 1990, a taxa equivalia a 13\%, todavia, 26 anos depois, houve uma evolução para $37 \%$, com variação equivalente a $24 \%$. Esse estudo também concluiu que, entre os anos de 2010 a 2016, a taxa de aumento do desflorestamento correspondeu a 7\%, e foi o período com maior crescimento em comparação com anos anteriores. Por fim, o autor concluiu que, no intervalo analisado, foram desflorestados 59.507,2 ha de áreas de vegetação nativa, o que indicou uma tendência de continuidade da expansão agrícola na área de estudo.

Em pesquisa realizada por Mengatto Junior; Oliveira; Silva (2017) no município de Marabá - PA, a avaliação de dados do PRODES Digital para o município, indicou que, houve aumento das áreas desflorestadas, mapeadas ao longo de quinze anos analisados (2000 a 2015), pois, evoluiu de $5.818,9 \mathrm{~km}^{2} \mathrm{em} 2010$ para um total de $8.533,5 \mathrm{~km}^{2}$ em 2015. Quanto a taxa do incremento do desflorestamento, em Marabá houve um acréscimo de 46,6\%, já no município de Paragominas - PA, esse acréscimo foi de $4,01 \%$.

Disponível em: https://www.nucleodoconhecimento.com.br/engenharia-ambiental/externalidadespositivas 


\subsection{QUANTO AS EXTERNALIDADES POSITIVAS E NEGATIVAS NO MUNICÍPIO DE PARAGOMINAS - PA}

\subsubsection{CRESCIMENTO DO PIB PER CAPITA}

Referente a relação do avanço do valor da produção de soja, observou-se também uma propensão à evolução no PIB do município de Paragominas (Tabela 2).

Tabela 2 - Dados de produção de soja e PIB no município de Paragominas - PA.

\begin{tabular}{|l|l|l|}
\hline Ano & Produção de soja (t.) & PIB (R $\$)$ \\
\hline $\mathbf{2 0 0 8}$ & 35.160 & 4.290 .238 .000 \\
\hline $\mathbf{2 0 0 9}$ & 42.600 & 3.467 .596 .000 \\
\hline $\mathbf{2 0 1 0}$ & 71.820 & 6.453 .706 .230 \\
\hline $\mathbf{2 0 1 1}$ & 119.515 & 7.322 .330 .400 \\
\hline $\mathbf{2 0 1 2}$ & 123.740 & 4.598 .608 .690 \\
\hline $\mathbf{2 0 1 3}$ & 121.800 & 3.095 .759 .160 \\
\hline $\mathbf{2 0 1 4}$ & 121.800 & 5.605 .753 .640 \\
\hline $\mathbf{2 0 1 5}$ & 275.500 & 6.684 .730 .690 \\
\hline
\end{tabular}

Fonte: elaborado pelos autores (2018) a partir de dados contidos no IBGE (2017b).

Os dados indicaram uma evolução do PIB local, de $\mathrm{R} \$ 4.290 .238 .000,00$, com produção de soja equivalente a 35.160 toneladas no ano de 2008, para um PIB de R $\$$ 6.684.730.690,00, com produção de soja igual a 275.500 toneladas no ano de 2015. Quanto a análise dos dados específicos sobre o PIB de Paragominas, esta indica que, de 2008 a 2015 ocorreu um incremento de 55,81\%. Neste caso, o crescimento do PIB no município, pode estar diretamente relacionado com o avanço da produção de soja, visto que tal atividade também apresentou taxa de crescimento (52.520 ha para 239.163 ha) nos três triênios analisados (2008-2010; 2011-2013; 2014-2016).

A pesquisa realizada em Dom Pedrito (RS), por Borges; Simões; Trindade (2016), indicou que o município apresentou bons índices socioeconômicos, com passagem RC: 42368

Disponível em: https://www.nucleodoconhecimento.com.br/engenharia-ambiental/externalidadespositivas 
do PIB de $\mathrm{R} \$ 605.054 .586,00$ e produção de soja equivalente a 39.600 toneladas em 2008, para $R \$ 977.858 .471,00$ e produção de soja igual a 180.900 toneladas em 2013. Assim como em Dom Pedrito - RS, os benefícios da produção da oleaginosa em Paragominas - PA, reflete-se na economia local, logo, o bom desempenho do PIB é uma externalidade positiva, proveniente da produção do grão em larga escala no município.

\subsubsection{EVOLUÇÃO DAS MATRÍCULAS ESCOLARES, NÚMERO DE ESCOLAS E DOCENTES CONTRATADOS}

Quanto à evolução das matrículas escolares, número de escolas e docentes contratados no município de Paragominas, os dados analisados indicaram uma tendência de diminuição desses quesitos (Figura 4).

Figura 4 - Evolução do número de matrículas realizadas, número de escolas e docentes contratos em Paragominas - PA.

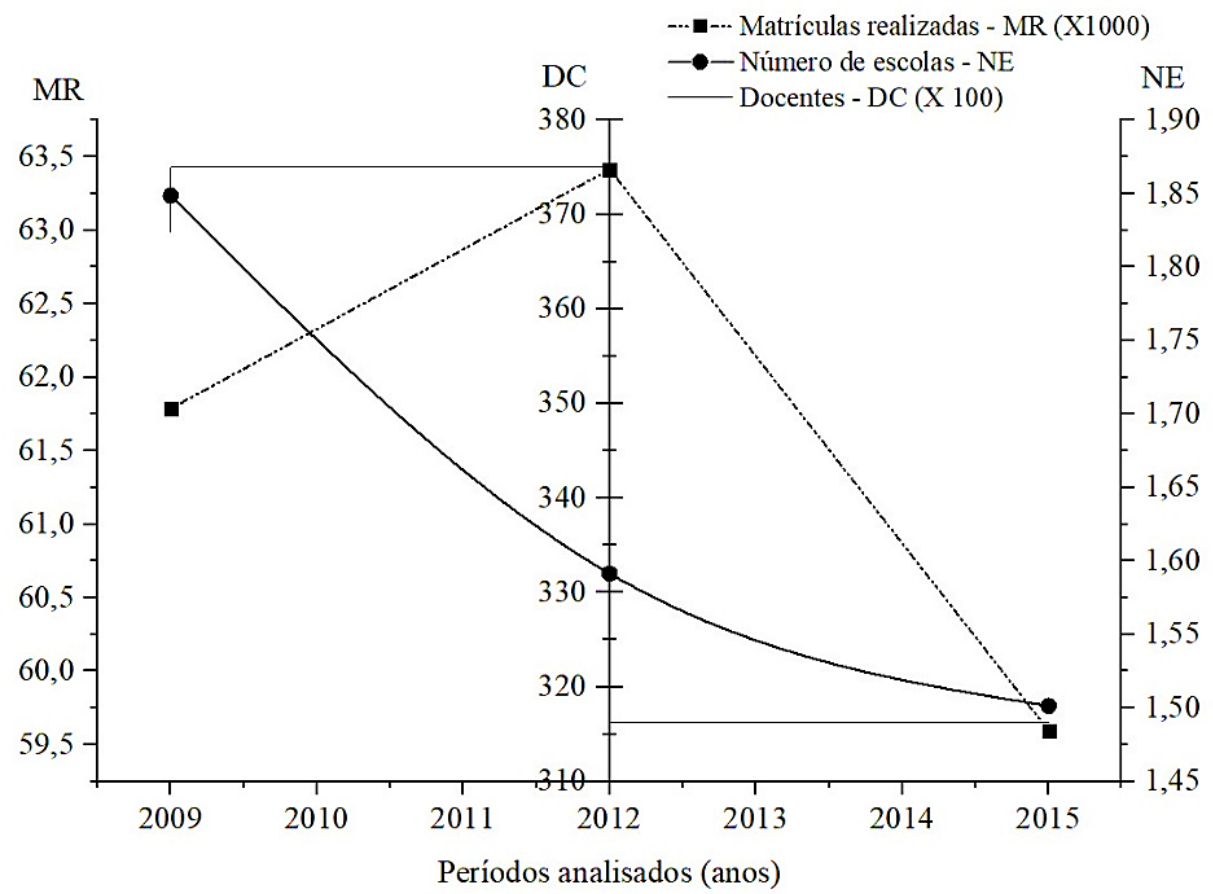

Fonte: IBGE (2017b).

Disponível em: https://www.nucleodoconhecimento.com.br/engenharia-ambiental/externalidadespositivas 
Quanto a análise de dados relacionados à quantidade de matrículas realizadas, escolas e docentes, destaca-se que:

(1) Houve variação no número de matrículas nos anos observados, com 61.786 mil matrículas em 2009, 63.414 mil em 2012 e 59.596 mil em 2015;

(2) ocorreu uma diminuição no número de escolas, pois em 2009 havia 372, em 2012, regrediu para 332, enquanto em 2015, contabilizou apenas 318 escolas e,

(3) em relação ao número de docentes contratados, em 2009 havia um total de 1.824, 1.868 em 2012 e, em 2015, havia 1.490 docentes contratados.

Em relação ao número de matrículas efetuadas e docentes contratados no município, percebeu-se um maior desempenho destes quesitos no ano de 2012. Nesse mesmo ano, o valor da produção de soja cresceu em mais de $56 \%$ em relação ao ano anterior, logo, houve aumento no PIB da agropecuária; no entanto, o aumento da produtividade de soja representou apenas 3\% do PIB do município de Paragominas. Dessa forma, não representou significativo aumento para o PIB municipal, e assim, não foi um fator determinante para o incremento no número de matrículas e contratação de docentes. Tal acréscimo nesse ano, pode estar vinculado a fatores como o melhor desenvolvimento de outros setores econômicos (Ex.: atividade madeireira, produção de carvão, reflorestamento, mineração de bauxita, indústria e serviços), os quais não foram objeto deste estudo.

Um estudo no município de Porto Nacional (TO), efetuado por Silva e Rodrigues (2016), analisou os principais impactos sociais gerados no município em decorrência do cultivo de soja para a produção de biodiesel e, vinculou a maior arrecadação de verba às melhorias na educação. $O$ estudo concluiu que, quanto maior a receita do município, maior seria a disponibilidade de serviços públicos e, por conseguinte, maior a infraestrutura urbana. Dessa forma, haveria aumento na infraestrutura educacional e diminuiria a evasão escolar. No município de Paragominas, esse efeito em cadeia não foi evidente, pois, nos anos com melhor desenvolvimento econômico, no período analisado, houve diminuição de fatores importantes para a educação, ou seja, o

Disponível em: https://www.nucleodoconhecimento.com.br/engenharia-ambiental/externalidadespositivas 
investimento nesse setor não perfaz uma externalidade positiva oriunda da evolução da sojicultura no município.

\subsubsection{CORRELAÇÃO ENTRE A ÁREA PLANTADA DE SOJA E A ÁREA DESFLORESTADA}

A Correlação de Pearson permitiu averiguar a relação das significâncias entre a área plantada com o cultivo de soja e a área desflorestada no município de Paragominas (Figura 05).

Figura 5 - Correlação entre a área plantada de soja e a área desflorestada no município de Paragominas - PA.

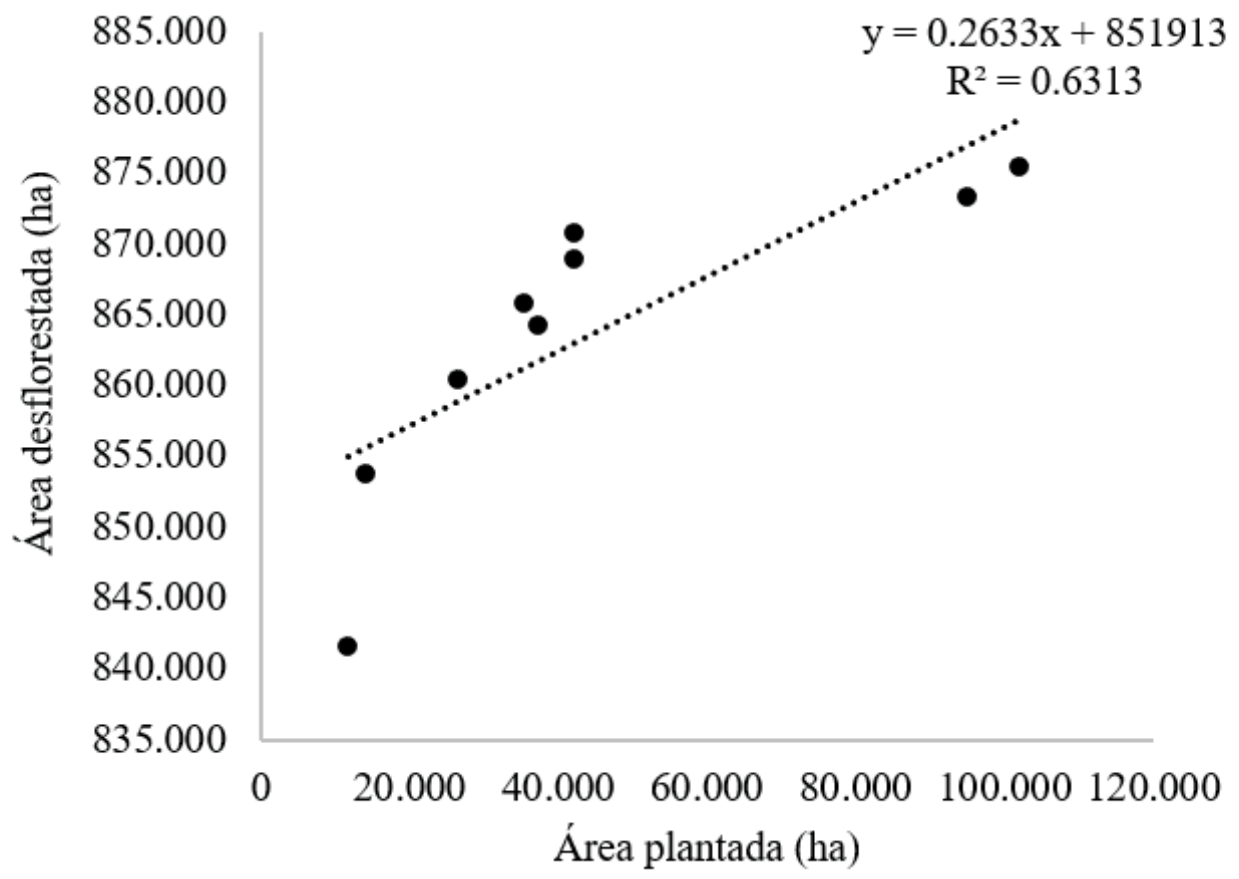

Fontes: PRODES (2017) e IBGE (2017b/).

Para a análise da área plantada de soja e área desflorestada, os dados indicaram uma correlação positiva qualificada como forte $(r=0,81)$. Tais dados permitem inferir que há uma relação direta entre os totais da área plantada de soja e o incremento do desflorestamento em hectares, ou seja, quanto se desmatou a cada ano, no que tange ao processo de desenvolvimento agrícola em Paragominas.

RC: 42368

Disponível em: https://www.nucleodoconhecimento.com.br/engenharia-ambiental/externalidadespositivas 
Os estudos efetuados nos municípios abaixo (Tabela 3) apresentam uma correlação de Pearson ( $r$ ) estabelecida no intervalo de 0,81 a 0,99 .

Tabela 3 - Valores de Coeficiente de Pearson ( $r$ ) em municípios dos Estados de: Mato Grosso - MT e Pará - PA.

\begin{tabular}{|l|l|}
\hline Municípios & $r$ \\
\hline Sinop - MT & 0,85 \\
\hline Sorriso - MT & 0,99 \\
\hline São Félix do Xingu - PA & 0,81 \\
\hline
\end{tabular}

Fontes: Brum; Dalfovo; Benfica (2011), Giaretta (2017) e Magno et al. (2013).

Os valores de $(r)$ encontrados por Brum; Dalfovo; Benfica (2011) no município de Sinop. em Mato Grosso, $(r=0,85)$; Giaretta (2017) em Sorriso, no mesmo estado ( $r=$ 0,99), e Magno et al. (2013) em São Félix do Xingu, no Pará $(r=0,81)$, foram consoantes ao encontrado em Paragominas $(r=0,81)$, pois verificou-se uma forte correlação entre as tendências de aumento da área ocupada pelo plantio da soja e a área desflorestada (estabelecido no intervalo de 0,81 a 0,99). Em Paragominas, a área desflorestada e a área para o cultivo da oleaginosa, aumentam praticamente na mesma proporção, por isso, o desflorestamento, é uma externalidade negativa derivada do avanço da sojicultura no município.

\subsubsection{CORRELAÇÃO ENTRE DESFLORESTAMENTO E PRECIPITAÇÃO TOTAL}

Os dados obtidos e analisados para o desflorestamento e a precipitação total em Paragominas, mostraram tendências de crescimento para o desflorestamento e diminuição para a precipitação nos triênios analisados (Figura 06). 
Figura 6 - Relação entre desflorestamento e a precipitação total em Paragominas PA.

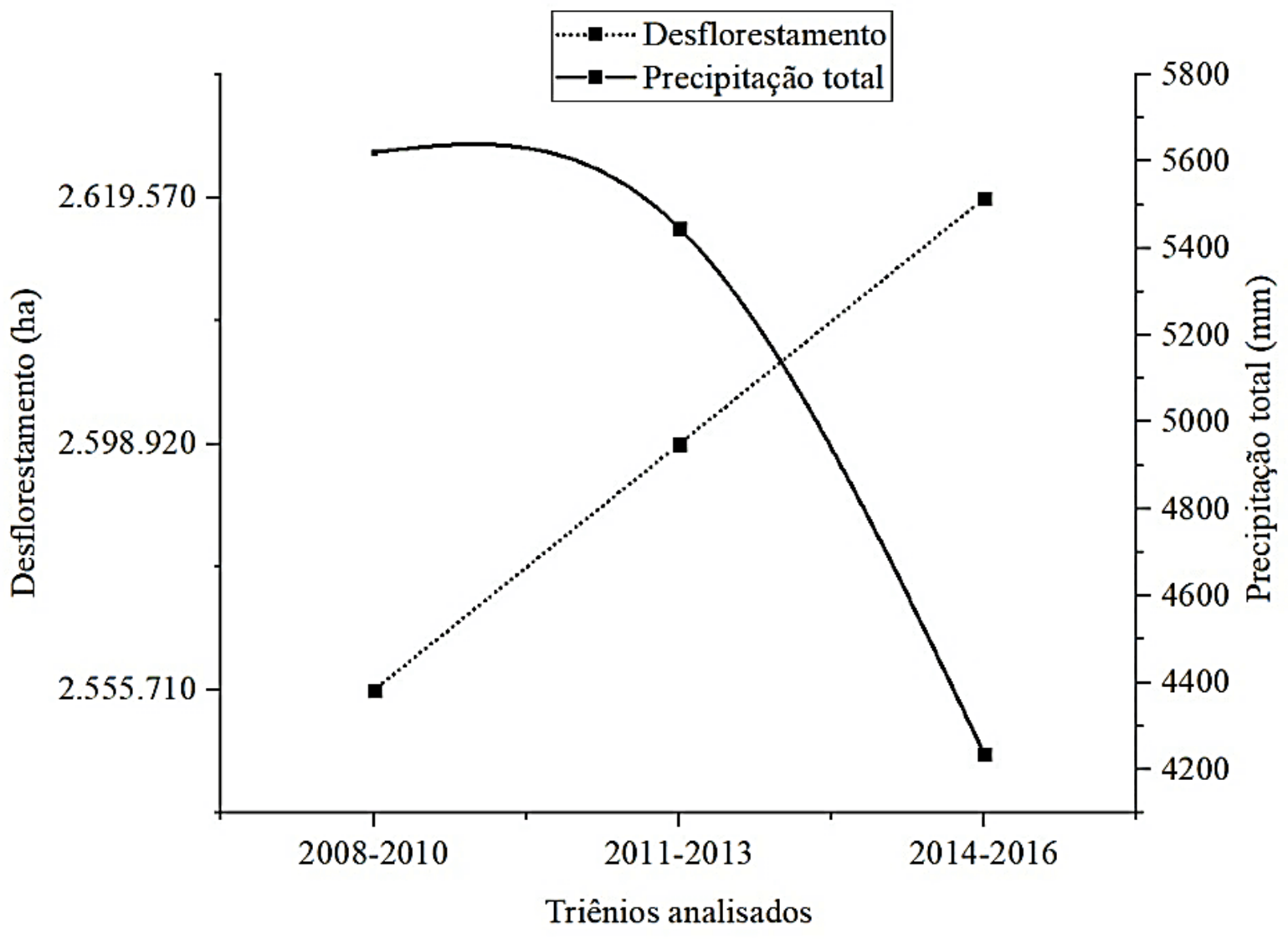

Fontes: PRODES (2017) e HidroWeb (2018).

A variação da precipitação atingiu níveis extremos, com um máximo de 5.621,4 mm no primeiro triênio (2008-2010), e um mínimo de 4.234,6 mm no terceiro triênio (20142016). No entanto, a variação da precipitação pode estar relacionada com diversos fatores além do desflorestamento como, por exemplo, a presença de La Niña e as atividades antrópicas.

Quanto a análise da correlação de Pearson $(r)$ entre as variáveis desflorestamento e precipitação, os dados indicaram que há uma relação inversamente proporcional ( $r=$ - 0,37), logo, adjetivada como uma relação fraca, ou seja, guardam uma determinada independência entre elas. Assim, o desflorestamento não influencia de forma significativa o nível de precipitação no município de Paragominas (PA).

Disponível em: https://www.nucleodoconhecimento.com.br/engenharia-ambiental/externalidadespositivas 
O estudo de Santos, C; Satyamurty; Santos, E. (2012), efetuado em Manaus (AM), concluiu que, no contexto amazônico, as mudanças climáticas podem estar relacionadas tanto com atividades referentes ao uso e ocupação do solo, quanto a fenômenos naturais como o El Niño e La Niña. No município de Paragominas, as condições atmosféricas, em especial a precipitação, podem estar relacionadas às variações climáticas globais, decorrentes de causas naturais. Dessa maneira, o desflorestamento não é o principal agente causador da variação de precipitação local, portanto, não é considerada uma externalidade negativa decorrente do avanço da monocultura da soja.

Portanto, uma das formas de amenizar a principal externalidade causada pela monocultura de soja, o desflorestamento, é aplicar técnicas de cultivo consideradas mais sustentáveis, que promovam o equilíbrio no uso do solo para atividade econômica como, por exemplo, o Plantio Direto, seguido de Inoculação de sementes para Fixação Biológica do Nitrogênio (FBN). Assim, com o aumento da produtividade do grão, não haverá necessidade da abertura novas áreas para cultivo a fim de suprir a demanda de produção (BULEGON et al., 2016; LOSS et al., 2011).

Outra, é o aproveitamento de áreas já desflorestadas é um dos fatores que podem elevar o incremento nesse tipo de ação e, dessa forma contribuir para a conservação da biomassa vegetal nativa, evitar a perda de novos habitats, bem como, determinar a conservação da diversidade biológica desse município, além de contribuir para a conservação das Áreas de Preservação Permanente (APP's), especialmente dos dois corpos hídricos municipais (Rio Uraim e Rio Paragominas/Prainha).

\section{CONCLUSÃO}

A sojicultura gerou externalidades à sociedade na qual foi inserida. Dentre elas, o aumento do PIB municipal, a partir do incremento na economia local provocado pela sojicultura no período de 2008 a 2016.

Quanto as externalidades negativas, foi comprovada a correlação entre o avanço da área plantada de soja e o desflorestamento em Paragominas. No entanto, deve-se RC: 42368

Disponível em: https://www.nucleodoconhecimento.com.br/engenharia-ambiental/externalidadespositivas 
ressaltar que podem existir outras variáveis como, por exemplo, a pecuária, a atividade madeireira e a produção de outras culturas no município, que influenciaram no aumento da área desflorestada, mas que não foram objetos de análise nessa pesquisa.

Os dados gerados por este estudo, referentes ao incremento da área plantada de soja, o aumento da área desflorestada e do PIB municipal, a alteração do número de matrículas efetuadas e docentes contratados, a diminuição do número de escolas e, a variação da precipitação local, são reais e irão possibilitar a continuação de estudos futuros que envolvam a dinâmica da sojicultura.

\section{REFERÊNCIAS}

ABDALA, K. O.; RIBEIRO, F. L.; FERREIRA M. E. Risco de impactos ambientais gerados pela dinâmica de uso do solo. Revista Brasileira de Cartografia, Monte Carmelo, v. 68, n. 2, p. 235-252, 2016.

AGÊNCIA NACIONAL DE ÁGUAS. PORTAL - ANA. Portal HidroWeb. Disponível em: $<$ http://www.snirh.gov.br/hidroweb/publico/apresentacao.jsf>. Acesso em: 22/95/2018.

ALMEIDA, L. C. B. Teoria economia ecológica. In: Pereira, R. S. (Org.). Gestão para o desenvolvimento econômico sustentável. São Paulo: Globus, 2013.

ALVES, L. W. R.; CARVALHO, E. J. M.; SILVA, L. G. T. Diagnóstico agrícola do município de Paragominas, PA. Belém: Embrapa- Amazônia Oriental, 2014.

ANTUNES, D. Externalidades negativas sobre o meio ambiente: processos econômicos de custeio. Revista de Ciências Gerenciais, São Paulo, v.13, n. 18, p.57-73, 2009. 
ARAÚJO, R. C. Análise sobre a monocultura de soja e o desenvolvimento sustentável na Amazônia com base na teoria do desenvolvimento endógeno. Revista Economia e Desenvolvimento, Santa Maria v. 26, n. 1, p.106-118, 2014.

ARAÚJO, R. C.; PONTE, M. X. Agronegócios na Amazônia: ameaças e oportunidades para o desenvolvimento sustentável da região. Revista de Ciências Agroambientais, Alta Floresta, v. 13, n. 2, p.101-114, 2015.

ARTAXO, P. et al. Perspectiva de pesquisas na relação entre clima e o funcionamento da floresta amazônica. Ciência e Cultura, Campinas, v. 66, n. 3, p. 41-46, 2014.

AYRES, M. et al. BioEstat 5.0: aplicações estatísticas nas áreas das ciências biológicas e médicas. Belém: MCT; IDSM; CNPq, 2007. 364 p. il. Acompanha CDROM.

BALBINOT JUNIOR, A. A. et al. Análise da área, produção e produtividade da soja no Brasil em duas décadas (1997-2016). Londrina - PR: Embrapa Soja, 2017.

BORGES, S. C.; SIMÕES, F. S. B.; TRINDADE S. L. A Relação entre a Produção de Soja e o PIB no município de Dom Pedrito/Rs. Revista Agropampa, Dom Pedrito, v.1, n. 2, p. 169-180, 2016.

BROCHADO, M. L. C. Avaliação de cenários de desmatamento para o estado do Pará. 2017, 44 p. Dissertação (Mestrado em geografia) - Universidade de Brasília UNB, Brasília - DF, 2017.

BRUM, A. L.; DALFOVO, W. C. T.; AZUAGA, F. L. Alguns impactos da expansão da produção de soja no município de Sorriso-MT. Revista Desenvolvimento em Questão, ljuí,v. 7, n. 14, p. 173-200, 2009.

BRUM, A. L.; DALFOVO, W. C. T.; BENFICA, V. C. A relação entre o desenvolvimento e o crescimento das culturas de grãos no município de Sinop-MT: uma análise para o período de 1984 a 2009. Revista Desenvolvimento em Questão, ljuí, v. 9, n. 17, p.159-190, 2011.

Disponível em: https://www.nucleodoconhecimento.com.br/engenharia-ambiental/externalidadespositivas 
BULEGON, L. G. et al. Componente de produção e produtividade da cultura de soja submetida à inoculação de Bradyrhizobium e Azospirillum. Revista Terra Latinoamericana, Chapingo - Estado do México, v. 34, n. 2, p. 169-176, 2016.

CPT. Comissão Pastoral da Terra Relatório. "Conflitos no campo 2016”. 2016. Disponível em:<https://www.cptnacional.org.br/component/jdownloads/summary/41conflitos-no-campo-brasil-publicacao/14061-conflitos-no-campo-brasil-2016>. Acesso em: 08/06/2018.

DALL'AGNOL, A. A soja no brasil: evolução, causas, impactos e perspectivas. Congresso de la soja del Mercosur, 5.; FORO DE LA SOJA ASIA, 1, Rosario. Un grano: Un universo. [Rosário: Asociación de la cadena de la soja Argetina], 2011.Disponível em: <http://ainfo.cnptia.embrapa.br/digital/bitstream/item/47515/1/amelio.soja.2011.pdf>. Acesso em: 08/06/2018.

DELAZERI, L. M. Determinantes do desmatamento nos municípios do Arco Verde Amazônia Legal: uma abordagem econométrica. Revista Economia-Ensaios, Uberlândia, v. 30, n. 2, p. 11-34, 2016.

DERANI, C.; SCHOLZ, M. C. A Injustiça ambiental das externalidades negativas das monoculturas para commodities agrícolas de exportação no Brasil. Revista Direito Agrário e Agroambiental, Maranhão, v. 3, n. 2, p. 1-25, 2017.

DEUS, R. M.; BAKONYI, S. M. C. O. Impacto da agricultura sobre o meio ambiente. Revista Eletrônica em Gestão, Educação e Tecnologia Ambiental, Santa Maria, v. 7, n. 7, p. 1306-1315, 2012.

DOMINGUES, M. S.; BERMANN, C. O Arco do desflorestamento na Amazônia: da pecuária à soja. Ambiente e Sociedade, São Paulo, v. 15, n. 2, p. 1-22, 2012.

EMBRAPA. Empresa Brasileira de Pesquisa Agropecuária. Perspectiva agrícolas no Brasil: desafios da agricultura brasileira 2015-2024. Capítulo 2 - Agricultura 
Brasileira: perspectivas e desafios. Brasília - DF: OCDE: FAO, 2015. 51p. Disponível em: <http://www.agri-outlook.org/>. Acesso em: 12/11/2017.

FERNANDES, P. A.; PESSÔA, V. L. S. O Cerrado e as suas atividades impactantes: uma leitura sobre o garimpo, a mineração e a agricultura mecanizada. Revista Eletrônica de Geografia, Rio Claro, v. 3, n. 7, p. 19-37, 2011.

FIRMINO, R. G.; FONSECA, M. B. Uma visão econômica dos impactos ambientais causados pela expansão da agricultura. Revista Econômica e Administração, São Paulo, v. 9, n. 18 p. 32-48, 2008.

FREDERICO, S. As cidades do agronegócio na fronteira agrícola moderna brasileira. Caderno Prudentino de Geografia, Presidente Prudente, v. 1, n. 33, p. 5-23,2011.

\section{GAZZONI, D. L. A sustentabilidade da soja no contexto do agronegócio brasileiro} e mundial. Londrina - PR: Embrapa, 2013.

GIARETTA, J. Produção agropecuária e suas interações com fatores ambientais, sociais e econômicos no município de Sorriso - Mato Grosso. 2017, 55 p. Dissertação (mestrado em Ambiente e Sistema de Produção Agrícola) - Universidade do Estado de Mato Grosso - UNEMAT, Tangará da Serra, 55 p, 2017.

GONZALEZ, R. A. et al. A influência do evento El Niño-Oscilação Sul e Atlântico Equatorial na precipitação sobre as regiões Norte e Nordeste da América do Sul. Revista Acta Amazônica, Manaus, v. 43, n. 4, p. 469-480, 2013.

GRANZIERA, M. M.; SAES, M. S. M. Um estudo da contribuição da agricultura multifuncional para o desenvolvimento rural sustentável. Revista de Gestão Ambiental e Sustentabilidade, São Paulo, v. 3, n. 1, p. 60-70, 2014.

IBGE. Instituto Brasileiro De Geografia E Estatística. Bases Cartográficas. Brasília, DF. 2017a. Disponível em: <https:// mapas.ibge.gov.br/bases-ereferenciais/basescartograficas/mapas-municipais>. Acesso em: 02 mai. 2018. 
IBGE. Instituto Brasileiro De Geografia E Estatística. Cidades@. Brasília, DF. 2017b. Disponível em: < https://cidades.ibge.gov.br/ >. Acesso em: 20/10/2017.

INPE. Instituto Nacional de Pesquisas Espaciais. PRODES DIGITAL, Desflorestamento nos Municípios da Amazônia Legal para o ano de 2016. 2017. Disponível em: <http://www.dpi.inpe.br/prodesdigital/prodesmunicipal.php>. Acesso em: 18/10/2017.

IRIGARAY, C. T. et al. O Pantanal Matogrossense enquanto patrimônio nacional no contexto das mudanças climáticas. In: SILVA, S. T., CUREAU, S.; LEUZINGER, M. (Orgs.). Mudança do Clima. Desafios jurídicos, econômicos e socioambientais. São Paulo: Fiuza, 2011.

KUPLICH, T. M.; CAPONE, V.; COSTA, L. F. F. O avanço da soja no Bioma Pampa. Boletim Geográfico do Rio Grande do Sul, Porto Alegre, v. 32, n. 31, p. 83-100, 2018.

LOSS, A. et al. Agregação, carbono e nitrogênio em agregados do solo sob plantio direto com integração lavoura-pecuária. Pesquisa Agropecuária Brasileira, Brasília, v. 46, n. 10, p. 1269-1276, 2011.

MAGNO, R. A. M. et al. Configuração espacial do desflorestamento em fronteira agrícola na Amazônia: um estudo de caso na região de São Félix do Xingu, estado do Pará. Revista Nera, Presidente Prudente, v. 16, n. 22, p. 96-110, 2013.

MATOS, P. F.; PESSÔA V. L. S. O Agronegócio no Cerrado do Sudeste Goiano: uma leitura sobre Campo Alegre de Goiás, Catalão e Ipameri. Sociedade e Natureza, Uberlândia, v. 24, n. 1, p. 37-50, 2012.

MENGATTO JUNIOR, E. A.; OLIVEIRA, R. C.; SILVA, J. O município de Marabá, PA frente ao ZEE na Amazônia Legal: avaliação das taxas de desmatamento. Embrapa Informática Agropecuária-Artigo em anais de congresso (ALICE). SIMPÓSIO BRASILEIRO DE GEOGRAFIA FÍSICA APLICADA, 17.; CONGRESSO NACIONAL 
DE GEOGRAFIA FÍSICA, 1., 2017, Campinas. Os desafios da geografia física na fronteira do conhecimento. Campinas: Unicamp, 2017.

MIRANDA, R. S. O Agronegócio da soja no Brasil: do Estado ao capital privado. Revista Novos Rumos Sociológicos, Pelotas, v. 2, n. 2, p. 122-141, 2014.

NOBRE, C. A. et al. Características do Clima Amazônico: Aspectos Principais. In: Keller, M. et al. (Eds). Amazonia and Global Change. Washington, DC: Geophysical Monograph, jan. 2019, p. 149-162.

OLIVEIRA NETO, A. A. Acompanhamento da safra brasileira. Companhia Nacional do Abastecimento (CONAB): Sexto levantamento, março 2017 - safra 2016/2017.: Brasília: Companhia Nacional de Abastecimento, 2017. Disponível em: < http://www.conab.gov.br>. Acesso em: 13/11/2017.

OLIVEIRA, C. M.; SANTANA, A. C. A governança no Arranjo Produtivo de Grãos de Santarém e Belterra, estado do Pará: uma análise a partir do grão soja. Revista de Economia e Sociologia Rural. Brasília, v. 50, n. 4, p. 683-704, 2012.

PAMPLONA, N. L. Mudanças no uso e cobertura da terra no município de Barreiras - BA entre 1990 e 2016. 2017. 44 p. Monografia (Graduação em Engenharia Ambiental) - Faculdade de Tecnologia, Universidade de Brasília. Brasília - DF. 2017.

PINTO, A. et al. Diagnóstico Socioeconômico e Florestal do município de Paragominas. Relatório Técnico. Belém - PA: Imazon, 2009.

PORTO. M. L.; JESUS, E. S.; PEREIRA JÚNIOR, A. Análise das tendências nas relações entre fluxo de veículos, arborização e os níveis de intensidade de ruído. Ecologia e Nutrição Florestal, Santa Maria, v.5, n. 3, p. 87-97, 2017.

PRODANOV, C. C.; FREITAS, E. C. Metodologia do trabalho científico: métodos e técnicas da pesquisa e do trabalho acadêmico. 2 ed. Novo Hamburgo - RS: Universidade Feevale, 2013. 
QUEIROZ, F. A. Impactos da sojicultura de exportação sobre a biodiversidade do Cerrado. Sociedade e Natureza, Uberlândia, v. 21, n. 2, p. 193-209, 2009.

RIVERO, S. et al. Pecuária e desmatamento: uma análise das principais causas diretas do desmatamento da Amazônia. Nova Economia, Belo Horizonte, v. 19, n. 1, p. 41-66, 2011.

SAKAMOTO, C. K.; SILVEIRA, I. O. Como fazer projetos e Iniciação Científica. São Paulo : PAULUS, 2014.

SANTOS, C. A. C.; SATYAMURTY, P.; SANTOS E. M. Tendências de índice de extremos climáticos para a região de Manaus-AM. Acta Amazonica, Manaus - AM, v. 42, n. 3, p.329-336, set. 2012.

SANTOS, S. R. Q. et al. Regime térmico e hídrico do solo para área de floresta tropical em anos de El Niño e La Niña, Caxiuanã-PA: estudo de caso. Revista Brasileira de Meteorologia, São Paulo, v. 26, n. 3, p. 367-374, 2011.

SEVERINO, A. J. Metodologia do trabalho científico. 24 ed. São Paulo: Cortez, 2017.

SILVA, C. A. F. Corporação e Agronegócio da soja na Amazônia. Revista ACTA Geográfica, Boa Vista, v. 2, n. 3, p.29-40, 2008.

SILVA, T. L. A.; RODRIGUES, L. H. Avaliação sistêmica dos impactos sociais da produção de soja para biocombustíveis na região central do estado de Tocantins. 2016. 140 p. Dissertação (mestrado em Engenharia de Produção e Sistemas) - Universidade do Vale do Rio dos Sinos, São Leopoldo - RS, 2016.

SILVEIRA, D. T.; CÓRDOVA, T. E. A pesquisa científica. In: Gerhardt, T. E.; Silveira, D. T. (Org.). Métodos de pesquisa. Porto Alegre: Editora de UFRGS, 2009, p. 31-42. 
SOUZA, L. M. et al. Avaliação do uso e cobertura da terra em Paragominas e Ulianópolis - PA, utilizando dados do projeto TERRACLASS. Revista Brasileira de Cartografia, Uberlândia, v. 3, n. 3, p. 421-431, 2017.

SOUZA, P. J. O. P.; ROCHA, E. J. P.; RIBEIRO A. Impactos do avanço da soja no balanço de radiação no leste da Amazônia. Acta Amazônica, Manaus, v. 43, n. 2, p. 169-178, 2013.

Enviado: Novembro, 2019.

Aprovado: Dezembro, 2019. 